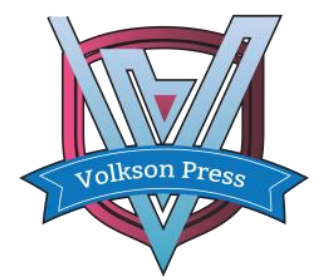

\author{
Contents List available at VOLKSON PRESS \\ Economics \& Management Innovations(EMI) \\ DOI : http://doi.org/10.26480/icemi.01.2017.202.203
}

\title{
Research on Capacity Requirements of IT Staff in Cloud Computing Environment
}

\author{
SUN Xiaona ${ }^{1 *}$, MIAO Hong ${ }^{1}$, and GE Shilun ${ }^{2}$
}

${ }^{1}$ School of Economics and Management, Jiangsu University of Science and Technology, Zhenjiang, P.R. China ${ }^{2}$ Yan Cheng Institute Of Technology, Yancheng, P.R. China

*just_sxn@163.com

This is an open access article distributed under the Creative Commons Attribution License, which permits unrestricted use, distribution, and reproduction in any medium, provided the original work is properly cited.

\section{ARTICLE DETAILS}

\section{Article History:}

Received 02 october 2017

Accepted 06 october 2017

Available online 11 october 2017

Keywords:

cloud computing; IT staff;

capacity requirements.

\section{ABSTRACT}

In recent years, the rise of cloud computing is very fast, it is the third technological innovation after the information technology and the Internet. And its proprietary features have new capabilities for IT personnel. According to describe the concept and characteristics of cloud computing, and based on the analysis of the characteristics of cloud computing technology and its influence on IT staff and the information description of IT job description of well-known recruitment website, the capacity of IT staff in cloud computing environment is discussed.

\section{Introduction}

As a new generation of IT technology, cloud computing is not only the third technological innovation after the information technology and the Internet, but also provides a new mode of service outsourcing for enterprises [1]. Cloud computing environment brings management changes to enterprises, which has new requirements for IT talents. This requires IT staff to have a clear goal for career development. According to analyzes the characteristics of cloud computing and the impact of cloud computing on IT personnel, as well as enterprises in the recruitment process for IT personnel requirements, this paper provides guidance for IT staff to understand what capacity they should have.

\section{The Concept and Characteristics of Cloud Computing}

Since 2007, IBM has officially put forward the concept of cloud computing, many experts, research organizations and related manufacturers give the definition of cloud computing from different research perspectives. Google believes that cloud computing is a system with open standards and Internet-based services which provides secure, fast and easy data storage and network computing services ${ }^{[2]}$. According to the National Institute of Standards and Technology, cloud computing is an application resource model that can be used to access configured computing resources over a network in a very simple way, which is provided by the service provider at the lowest cost or professional operation of the rapid configuration and release ${ }^{[3]}$. In Linetal's opinion, cloud computing for applications and IT users, that is, "IT Service". Computing power, storage and application services are sent from the data center to the user through the Internet; For Internet application developers, that is, the Internet-based software development platform; for infrastructure providers and managers, that is, through the IP network to connect the distributed data center infrastructure ${ }^{[4]}$.

Fundamentally, cloud computing is the development of grid computing, parallel computing, distributed computing, and the commercialization of scientific concepts. Cloud computing is usually defined as an Internetbased value-added services, including infrastructure services, platform services, software services, involving the network, server applications ${ }^{[5]}$. With the development of cloud computing and network computing, the professional orientation of IT staff changes from professional technical services to enterprise terminal services [6]. Cloud computing has the following characteristics:

(1) On-demand self-service. Consumers do not need to interact with a service provider to automatically get their own computing resources such as server time, network storage, etc.

(2) Virtualization services. Cloud computing is a set of computing, storage, server, application software which seem as one of the resources of virtualization, support different clients to improve the network access available capacity. Users do not need to understand the actual location of the application, the application runs in the cloud.

(3) The allocation of independent resource pool. According to the needs of consumers to dynamically divide or release different physical and virtual resources, these pooled vendor computing resources provide services with multi-tenant model. Users often do not control or understand the exact division of these resource pools, but they may know the pool of resources in which administrative area or data center such as storage, computing, memory, network bandwidth, and the number of virtual machines.

(4) Fast elasticity. The ability to provide the same resources is to release resources quickly and flexibly. For consumers, this ability is unlimited and can be purchased at any time in any quantifiable way.

(5) Service measurable. The cloud system automatically controls and optimizes resource usage by means of metering. The use of resources can be monitored, controlled, and transparent to suppliers and users.

(6) Potential dangers. Cloud computing provides storage services in addition to computing service, data security is still a big problem [7]. Government agencies and business organizations with sensitive data should be highly vigilant in selecting cloud computing services.

\section{The Impact of Cloud Computing on IT Staff}

Cloud computing is the latest technology in the development of IT, and it is the inevitable product of IT industry. Cloud computing is seeping into the daily management and development model of IT technology, and is impacting IT departments and personnel more or less. Although it has been predicted that the widespread adoption of cloud computing will cause IT layoffs, but in fact, the demand for personnel in the IT sector is still increasing in recent years. In addition, there are two aspects that cloud computing have influenced the IT staff:

(1) IT staff specialization, reduce the workload within the IT department, and increase coordination work outside the IT department ${ }^{[8]}$. Any 
information system, in addition to some small and medium-sized enterprises without exclusive IT personnel, needs some adjustments and maintenance, which is provided by the outsourcing provider. In the process of introducing cloud computing, enterprises still need IT department-related personnel involved, the only way to integrate the internal IT organization, which also need to take into account crosssoftware applications, or will encounter some of the technical problems which cloud software does not provide. That is, many departments of the user to use their own cloud software, making the IT department has a technical work other than the work of the content.

(2) Change the role of IT staff. According to CEB, traditional IT roles, such as developers, data center administrators, and network administrators, may disappear in the corporate IT department. But the disappearance of these roles does not mean the simplification of the staff, and new IT role types will be replaced to replace traditional technical roles according to the survey of CEB. IT departments will be more demanding "service managers" to identify the different parts of the business work to help IT purchase the right IT system, the organization will need IT professionals to make the company's IT system easier to use. From this perspective, the IT department staff has not been streamlined, they just to achieve the role of change to adapt to changes in organizational structure and responsibilities ${ }^{[9]}$.

\section{Requirements for IT Staff in Cloud Computing Environment}

According to the characteristics of cloud computing technology, the author conduct a comprehensive analysis of the well-known recruitment website 51Job related job information of the Internet, the enterprise in the recruitment process of IT staff capacity of the general requirements are concluded through the word frequency analysis, as shown in Fig.1, it can be seen that in the description of the key words of IT staff job requirements, the main capacity requirements are data, system, design, technology, development, framework, virtualization and so on.

\section{Responsible Service

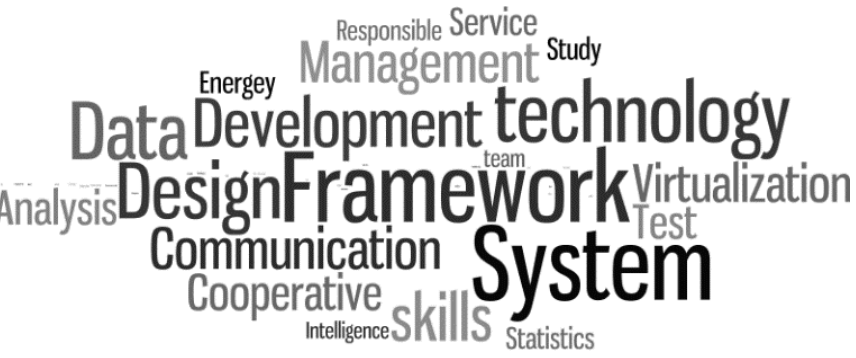

Fig. 1: The Key Words of IT Employee Competency Requirements

Through the elaboration and analysis of the content on the above, we can see that the requirements of the cloud computing environment for IT personnel are as follows:

(1) IT staff need to improve their professional knowledge and skills and master key technologies. a) On-demand self-service and virtualization is the two major characteristics which cloud computing is different from the traditional of outsourcing, so IT staff need to develop and expand the skills of multiple platforms and applications, they not only need to master the traditional IT technology, but also need to use all kinds of skilled virtual machine, fast switching between different systems, whenever and wherever possible access to resources from the remote development. b) As the growth of cloud platform users, the greater demands were being placed on the data center server and operating system shelves deployment, equipment maintenance and operation and maintenance, responsible for cloud system platform monitoring, daily troubleshooting and performance optimization, responsible for the server, cloud system performance testing work, which result in platform management and maintenance technology has become the necessary skills for IT staff. c) Cloud computing systems require parallel services for a large number of users, distributed, high throughput and high transmission rate are the characteristics of the explosive growth of various data and storage technology, and most of the cloud computing platform will provide for unstructured and semi-structured data storage the way. So IT staff must master the new database management system and familiar with the new network storage technology to build a computing resource pool. d) In the process of using cloud computing, the security problem is not only including data security, it is a complex problem involving credibility, system, technology, laws and regulatory aspects, IT personnel need to master more information security techniques, such as anti-virus, Trojan horse technology.

(2) IT staff not only need to possess professional IT skills, but also need to have a certain management capacity. Cloud computing providers IT staff must master the key technologies of cloud computing, the use of cloud services IT staff responsible for the local system and the cloud to maintain contact, focus of attention shifted from specific technical details to the core business of enterprises, and their positions gradually shifted from technical specific positions to business end jobs. Therefore, in the process of the introduction of cloud services, enterprises need to clear the business needs of the IT department, and clear business needs for business units to make recommendations and communicate with suppliers to help IT procurement of the right IT system to meet the requirements of enterprises tailored services, which requires the IT Department staff have negotiation skills, communication skills, management ability and contract financial skills, which helps the management of suppliers.

(3) IT staff need continuous learning ability and innovative thinking. In the era of cloud computing, IT talents must always maintain innovative thinking, development thinking and comprehensive thinking. There is a large demand for talent in cloud computing. To obtain a better result in the future training, it is not useful for IT employees to use the traditional method, but through continuous learning new knowledge and maintain continuous innovation in the cultivation of thinking, changing from the past "a multi-skilled" to "multi-skilled" type of talent.

\section{Conclusions}

As an important information infrastructure, cloud computing is the trend of IT technology development, and it puts forward higher requirements for IT staff capability, Based on the characteristics of cloud computing and its impact on IT employees, this paper summarizes the ability requirements of IT staff from the aspects of technology, management, learning and innovative thinking. Cloud computing is a technology revolution, which will cause new changes in many areas of social life, and the enterprises how to get to the employees who possess those abilities in the process of the recruitment is an important research content in the future.

\section{References}

[1] X. Yang, Framework of Enterprise IT Decision Mechanism in the Context of Cloud Computing, Journal of Computer System Application, Vol.15(11)(2013)13-18.

[2] Google, Google Apps Messaging and Collaboration Products, Security White paper, (2010).

[3] X. Z. Zhao, Concept, Technology Development and Application of Cloud Computing, Journal of Technical Exchange, Vol.93(3)(2017)193-194.

[4] J. Tang, Cloud Impact on IT Sector Size, Journal of Jinan Vocational College, Vol.12(3)(2014)81-82.

[5] Ln G, Fu D, Zhu Jetal, Cloud Computing: IT as a service, IT Professional Vol.11(2)(2009)10-13.

[6] X. L. Zhu, Requirements and Training System Design of New Compound IT Talents, Journal of Science and Management, Vol.18(5)(2011)68-70.

[7] W. Sun, Discussion on the Security of Cloud Computing, Journal of Computer age, Vol.16(8)(2014)5-7.

[8] Q. H. Li, Architecture and Key Technology Analysis of Cloud Computing, Journal of Electronic Production, Vol.2(4)(2014)102-105.

[9] W. L. Huang, Innovation of IT Talents Training Mode in Universities in Cloud Computing Era, Journal of Computer age, Vol.21(3)(2014)59-61. 